\title{
Ketika Fans 'Menikahi’ Idolanya: Studi Fenomenologi tentang Loyalitas Fandom BTS
}

\author{
Jennifer Riona, Nanang Krisdinanto \\ nangkris@ukwms.ac.id \\ Universitas Katolik Widya Mandala, Jl. Dinoyo 42-44 Surabaya
}

Submitted: 01 April 2021, Revised: 24 April 2021, Accepted : 19 Mei 2021

\begin{abstract}
Abstrak
Penelitian ini berfokus pada fenomena subkultur fandom, yaitu perilaku anggota Army Surabaya (kelompok penggemar grup K-Pop BTS yang berbasis di Surabaya), terutama terkait loyalitas terhadap grup idolanya. Pendekatan dalam penelitian ini adalah kualitatif, sedangkan metode yang digunakan adalah fenomenologi. Teknik pengumpulan data dilakukan melalui wawancara mendalam untuk memperoleh pemaknaan loyalitas yang diceritakan oleh Army Surabaya dari sudut pandang mereka sendiri. Hasil penelitian ini menunjukkan, loyalitas terhadap idola dimaknai sebagai kewajiban yang harus dilakukan secara tulus sebagai imbal-balik perjuangan idolanya. Teknologi informasi juga membuat relasi Army Surabaya dan idolanya juga telah melampaui kehidupan nyata, yang terlihat dari dianggapnya sang idola sebagai kekasih atau suami virtual. Mereka telah mengembangkan ikatan atau hubungan khusus dengan grup idolanya yang hanya dapat dirasakan diri mereka sendiri. Hasil penelitian juga menunjukkan, loyalitas Army Surabaya terhadap BTS telah mencapai tahapan yang disebut The Marriage.
\end{abstract}

Kata Kunci: fans; Army Surabaya; loyalitas; fenomenologi.

\section{When Fans "Marry" Their Idols: A Phenomenological Study of BTS Fandom Loyalty}

\begin{abstract}
This study focuses on the phenomenon of the fandom subculture, namely the behavior of members of the Surabaya Army (a group of fans of the K-Pop BTS group based in Surabaya), especially regarding loyalty to their idol group. The approach in this research is qualitative, while the method used is phenomenology. The data collection technique was carried out through in-depth interviews to obtain the meaning of loyalty that was told by the Surabaya Army from their own point of view. The results of this study indicate that loyalty to an idol is interpreted as an obligation that must be done sincerely in return for the struggle of the idol. Information technology has also made the relationship between Army Surabaya and its idol transcend real life, which can be seen from the fact that the idol is considered a virtual lover or husband. They have developed a special bond or relationship with their idol group that only themselves can feel. The results also showed that the Surabaya Army loyalty to BTS had reached a stage called The Marriage.
\end{abstract}

Keywords: fans; Army Surabaya; loyalty; phenomenology

\section{PENDAHULUAN}

Saat ini, gelombang Pop Korea atau K-Pop telah memasuki berbagai negara dan menjadi sorotan masyarakat. Secara global, penyebaran industri hiburan yang berasal dari Korea Selatan ini sudah terjadi sejak 1990-an. Melalui penyebaran tersebut, para artis atau selebriti Korea Selatan mulai menjadi idola di mana-mana termasuk di Indonesia. Dari gelombang K-Pop inilah kemudian lahir budaya baru dalam kelompok fans atau fandom yang merupakan produk interaksi dengan budaya K-Pop. (Juwita, 2018) 
Kalangan remaja menjadi kelompok masyarakat yang paling menggemari jenis musik K-Pop ini, atau genre music pop yang dilantunkan oleh boyband adal Korea Selatan. Yang disebut boyband di sini merujuk pada kelompok atau grup band yang memiliki anggota tiga orang atau lebih, dan mereka serempak menyanyikan lagu yang diselaraskan dengan grakan menari yang energik. Salah satu ciri khas lain dari boyband adalah mereka menyanyikan lagi tanpa memainkan alat musuk. Sebelum hadirnya gelombang boyband dari Korea Selatan, pada era 1990-an pasar musik Indonesia (khususnya di kalangan remaja) sudah mengenal sejumlah boyband yang berasal dari Amerika Serikat atau Eropa seperti Boyzone, New Kids on the Block, Westlife, Boyzone, dan sebagainya. (Cho, 2012).

Pada perkembangan berikutnya, banyak boyband asal Amerika Serikat dan Eropa tersebut bubar. Pada saat itulah, boyband asal Korea Selatan pada tahun 2000-an mulai memasuki pasar musik di Indonesia. Berbeda dengan boyband asal Amerika Serikat dan Eropa yang kebanyakan membawakan lagu bergenre pop, boyband Korea Selatan ini muncul dengan mengusung genre musik R\&B dan hip-hop. Pada masa awal-awal munculnya gelombang K-Pop, boyband yang dikenal sukses misalnya adalah Super Junior atau SuJu, dengan lagu hit-nya, Big Bang, yang sukses menembus pasar internasional.

Sebagai bagian dari interaksi, para boyband ini kemudian memberi julukan kepada fans-nya. Hal ini menyebabkan terbentuknya komunitas fans yang menggunakan nama-nama khas yang berasal dari julukan tersebut. Dari sinilah fenomena fans muncul, lalu semakin berkembang dengan pembentukan kelompok-kelompok fans yang disebut fandom. Fenomena ini muncul akibat terjadinya kesenangan yang secara intens terusmenerus diulang. Intensitas kesenangan yang diulang-ulang ini pula yang menjadi salah satu penanda budaya populer. (Fiske, 2011).

Fanatisme terhadap idola cenderung membuat fans memiliki keinginan mengkonsumsi semua hal yang terkait dengan idolanya, dan hal ini pelan-pelan menciptakan perilaku konsumtif. Hal ini didorong oleh berkembangnya teknologi informasi yang semakin memudahkan masuknya budaya populer tertentu. Merujuk Dults, Zwaan, dan Reijinders (dalam Sagita \& Kadewandana, 2018: 49), fandom memang mendapatkan fasilitas konsumtif melalui teknologi digital komunikasi. Teknologi inilah yang menyebarkan budaya populer dan menjadikannya sebagai budaya massa yang digemar dan dikonsumsi secara luas.

Menurut Yuniarti (2015), perilaku konsumtif adalah kegiatan membeli barang yang tidak sesuai kebutuhan, atau membeli sesuatu dengan dasar untuk memenuhi hasrat, keinginan dan kesenangan (bukan kebutuhan) yang sifatnya berlebihan. Hal ini bisa dilihat dalam perilaku fans. Mereka cenderung membeli album atau merchandise yang terkait dengan idolanya bukan sebagai bagian dari kebutuhan, melainkan sebagai bagian dari kesenangan atau keinginan. Hal ini juga dilihat sebagai bentuk komunikasi antara fans dengan idolanya.

Tanpa kepemilikan terhadap benda-benda tersebut, para fans cenderung merasa identitasnya sebagai penggemar tidak diakui. Hal inilah yang disebut Yuniarti (2015) bahwa perilaku konsumtif telah menjadi budaya dan bagian dari pemenuhan gaya hidup. Fans memerlukan benda-benda atau kegiatan tertentu untuk melengkapi identitas dan 
gaya hidupnya sebagai fans. Kepemilikan atau kegiatan yang terkait dengan idola tersebut dipahami sebagai sebagai bagian dari loyalitas terhadap idola. Secara tidak langsung, perilaku konsumtif dari fans seperti ini membentuk loyalitas. Loyalitas tersebut kemudian diekspresikan diantaranya melalui pembelanjaan terhadap barang-barang atau peristiwa yang terkait dengan idola. Merujuk McRobbie (2011), fans memang mengejar keinginan dan kenikmatan dalam gaya hidup yang membuat mereka tertarik kepada budaya populer.

Fans dengan loyalitas seperti inilah yang menjadi target konsumen bagi semua idola di Korea Selatan. Stanley (dalam Hurriyati, 2010: 138) menyebutkan, fans artis Korea Selatan ini digambarkan memiliki hubungan loyalitas dalam beberapa tahapan yang disebut The Relationship, The Courtship dan The Marriage. Tahapan-tahapan ini mencerminkan tahapan hubungan di antara fans dan idola, mulai tahapan yang menunjukkan adanya keinginan menahan diri dari fans hingga tahapan yang menggambarkan hubungan yang tidak lagi transaksional. Tahapan tersebut juga trending menunjukkan adanya hubungan jangka panjang yang tidak bisa dipisahkan antara idola dan fans. Dalam hubungan tersebut terdapat aspek loyalitas yang kemudian menciptakan ketergantungan fans kepada sang idola. Pada konteks ini, fans artis Korea Selatan bahkan dikenali sampai rela membelanjakan uangnya hingga puluhan juta rupiah hanya untuk mengikuti aktivitas idola dan membeli benda-benda terkait idolanya.

Kembali pada konteks K-Pop, setelah generasi awal yang diwakili oleh Super Junior kemudian bermunculan boyband baru yang tampil dengan gaya berbeda. Saat ini, yang menduduki puncak trending di masyarakat adalah boyband BTS, atau yang biasa dikenal sebagai Bangtan Boys. Boyband yang memulai debutnya pada 13 Juni 2013 ini dinobatkan menjadi grup idola nomor 1 di Korea Selatan dan sukses menembus pasar global. Untuk mendapatkan sukses global seperti ini, BTS telah melewati naik turunnya perjuangan yang tidak mudah. Ketujuh anggotanya harus melewati proses training selama bertahun-tahun. (Saputri, 2019)

Sebagaimana terjadi pada boyband lainnya, fenomena BTS juga diikuti munculnya kelompok fans atau fandom. Fans BTS kemudian diberi nama Army, singkatan dari Adorable Representative M.C for Youth. Rasa cinta Army kepada BTS ini membuat mereka mengikuti nyaris semua yang dilakukan oleh idolanya. (Cindoswari \& Diana, 2019: 278) Army dikenal sebagai salah satu kelompok fans yang paling fanatik. Gambar berikut bisa dijadikan cerminan dari apa yang dilakukan para fans BTS untuk mengekspresikan rasa cinta dan loyalitasnya. 


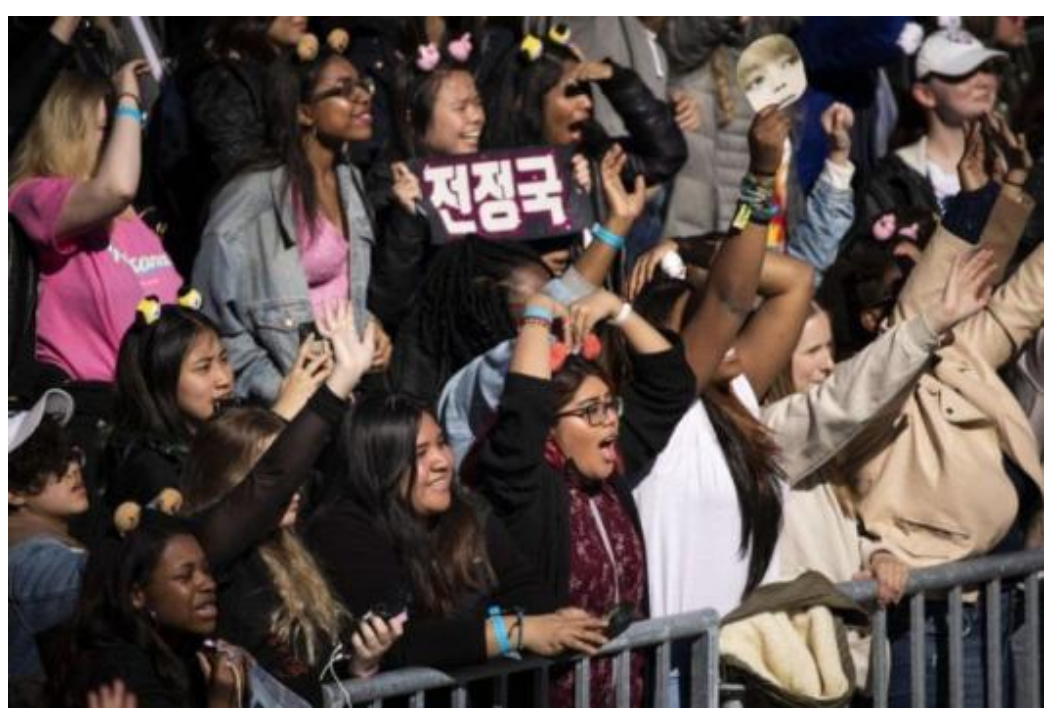

Sumber: Google, 2020

Gambar 1 Foto Army di Konser BTS

Seperti terlihat dalam gambar di atas, para fans BTS (Army) menunjukkan ekspresi dan tingkah laku tertentu di konser BTS. Misalnya dengan cara mengangkat tangan membentuk hati di atas kepala secara serempak, bersorak-sorai, membawa poster atau tulisan dengan pesan-pesan tertentu. Mereka menunjukkan rasa cinta dan loyalitasnya dengan segala cara. Dalam dunia hiburan, merujuk Jenkins (1992), fandom memang memiliki peran sangat penting. Tidak ada boyband di Korea Selatan yang tidak memiliki komunitas fans atau fandom, dan masing-masing kelompok memiliki identitas yang khas.

Fandom K-Pop memang dikenal luas memiliki karakter antusias dan loyal pada idolanya. Fans K-Pop bahkan dipandang bersikap berlebihan, gila, histeris, adiktif, terobsesi dan konsumtif. Mereka dianggap gemar menghamburkan uang untuk membeli benda-benda yang terkait idolanya, mengejar atau menguntit idolanya hingga ke manapun. Ekspresi atau perilaku tersebut dianggap sebagai bentuk kecintaan dan loyalitas mereka. Para fans mengekspresikan loyalitasnya melalui kepemilikan terhadap koleksi album, barang-barang tertentu, atau mendatangi konser-konser idola. Siapapun yang merasa dirinya sebagai fans sejati merasa memiliki kewajiban untuk mengenakan identitas atau tanda yang diberikan sang idola, baik berupa busana bertuliskan nama boyband idola, memajang poster idola di kamar, atau mengunggah foto-foto idola di akun media sosial.

Komunitas fans BTS yang disebut Army ini bahkan tanpa ragu membeli merchandise BTS yang harganya tidak mudah. Uang jutaan rupiah bisa dibelanjakan hanya untuk membeli album hingga tiket konser BTS di luar negeri. Itulah sebabnya muncul stereotip "alay" terhadap fans K-Pop, atau fanatisme yang berlebihan. Sikap fanatik ini, mengutip Chung, Beverland, Farrelly, dkk (dalam Pertiwi, 2013: 159) merupakan sikap yang bersikeras terhadap pemikiran atau ide-ide yang menganggap bahwa pendapatnya sendiri atau idolanya yang paling benar atau hebat. Karena itu, mereka mengabaikan argumentasi atau fakta yang bertentangan. Fanatisme membuat seseorang melupakan jati dirinya sendiri, dan membuat risau orang-orang di sekitarnya. 
Di sinilah teknologi informasi ikut menjadi sarana fans untuk berkomunikasi. Mereka membicarakan hal-hal seperti video klip baru, kegiatan idola, karya-karya idola yang baru, atau pengalaman dan cerita hidup mereka masing-masing.

Salah satu Fandom Army adalah Komunitas Army Surabaya yang berdiri sejak 30 Januari 2015. Komunitas ini dikelola oleh admin grup official Army Surabaya, dan mempunyai anggota sekitar 200 orang. Kegiatan rutinnya bermacam-macam. Misalnya membuat event pada hari spesial anggota BTS, kegiatan amal, atau sekadar pertemuan rutin. Sebagaimana komunitas lainnya, anggotanya menjadikan komunitas Army Surabaya sebagai wadah bertukar informasi, di antaranya mengenai merchandise BTS, video terbaru, dan berita terkait BTS. Sebagai anggota komunitas, anggotanya merasa mendapat keuntungan karena bisa memperoleh informasi dari anggota lainnya. Mereka merasakan adanya sisi positif menjadi fans BTS. Dalam konteks ini, kota Surabaya memang masuk ke dalam daftar 10 besar fans BTS paling setia di Asia Tenggara yang diukur dari jumlah penonton streaming di YouTube. (Widyastuti, 2018).

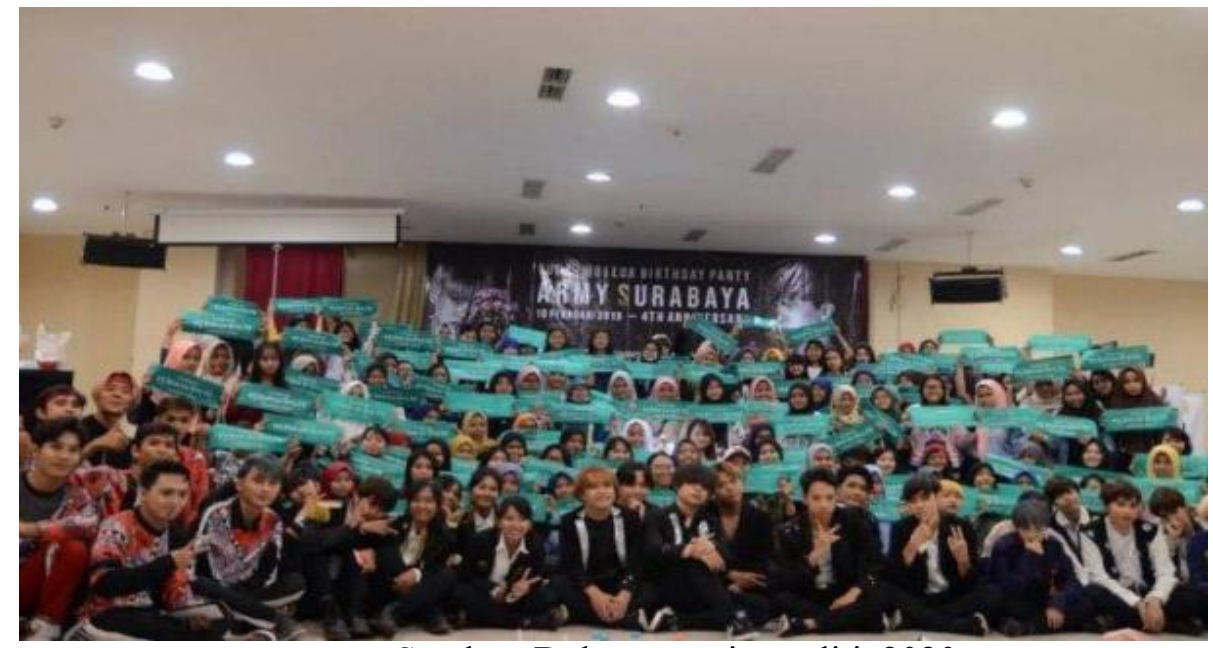

Sumber: Dokumentasi peneliti, 2020.

Gambar 2 Foto Army Surabaya Merayakan Ulang Tahun ke-4

Hal inilah yang menjadikan Army Surabaya menarik diteliti. Sebagai penelitian fenomenologi, penelitian ini menggambarkan ekspresi loyalitas fans BTS dari sudut pandang mereka sendiri; bagaimana para fans memaknai idolanya sebagai produk yang mengikat identitas mereka.

Kajian-kajian fandom Pop Korea di Indonesia ini sebetulnya cukup banyak dilakukan dari bidang ilmu yang berbeda, seperti Arundarti dkk. (2019), Cindoswari dan Diana (2019), Hapsari dkk. (2016), Juwita (2018), Pertiwi (2013), Putra dan Jusnita (2018), Rinata dan Dewi (2019), Sagita dan Kadewandana (2018), atau Veronica dkk. (2018). Penelitian-penelitian sebelumnya memiliki fokus yang berbeda-beda, baik terkait objek, subjek atau metode penelitian. Sedangkan penelitian ini mengambil objek, subjek serta metode penelitian yang berbeda dengan penelitian sebelumnya, yaitu objek pemaknaan terhadap loyalitas, subjek Army Surabaya, serta metode fenomenologi. Tujuannya adalah menguraikan cara anggota Army memaknai tindakan yang mencerminkan loyalitas yang selama ini mereka lakukan terhadap idolanya melalui pengalaman subjektif. 


\section{METODE PENELITIAN}

Penelitian ini menggunakan pendekatan kualitatif dan metode fenomenologi. Metode ini dipilih karena para subjek yaitu Army di Surabaya dilihat secara aktif membentuk makna dari pengalaman yang dilalui selama menjadi fans BTS. Sebagai metode, fenomenologi digunakan untuk menggali nilai-nilai dan pengalaman yang pernah dialami manusia. Fenomenologi, merujuk Husserl (dalam Barnawi \& Darojat, 2018), merupakan ilmu yang mempelajari kesadaran dari perspektif pokok seseorang yang merupakan pengalaman subjektif.

Teknik koleksi data dilakukan melalui wawancara mendalam tiga tahap, yaitu life history, pengalaman subjek, dan refleksi subjek terhadap pengalaman tersebut. (Seidman, 2006) Sebagai penunjang, peneliti juga melakukan observasi terhadap keseharian para subjek, termasuk koleksi-koleksi merchandise BTS yang dimiliki subjek. Data yang diperoleh diklasifikasi melalui tema-tema tertentu, dan dinarasikan dengan gaya bertutur.

Para subjek dalam penelitian ini subjek dipilih secara purposive, yaitu individu yang menjadi anggota Komunitas Army Surabaya. Mereka dipilih dengan pertimbangan memiliki pengalaman dalam aktivitas fandom BTS, dan sudah cukup dewasa untuk diminta memberi refleksi terhadap pengalamannya. Dengan pertimbangan tersebut, lima anggota Komunitas Army Surabaya dipilih sebagai subjek penelitian ini seperti tampak dalam tabel berikut.

\section{Tabel 1 Daftar Subjek Penelitian}

\begin{tabular}{|c|c|c|c|c|}
\hline NO. & NAMA & USIA & PEKERJAAN & KETERANGAN \\
\hline 1. & $\begin{array}{l}\text { Senja Ayu Novita } \\
\text { Dewi (Senja) }\end{array}$ & 26 & Karyawan & $\begin{array}{l}\text { Tergabung dalam group Army Indonesia } \\
\text { sebagai admin. } \\
\text { Memiliki } 15 \text { album BTS, serta puluhan } \\
\text { koleksi papercup dan photocard. Army } \\
\text { bomb, season greeting, official } \\
\text { membership, bt } 21 \text {, figure Jimin, Dicon, } \\
\text { BTS doll. } \\
\text { Pernah menonton konser BTS di Jakarta. }\end{array}$ \\
\hline 2. & $\begin{array}{l}\text { Tasya Cariza Tiara } \\
\text { Putri (Tita) }\end{array}$ & 18 & Siswi SMA & $\begin{array}{l}\text { Tergabung dalam group Army Surabaya. } \\
\text { Memiliki koleksi } 2 \text { album BTS, } \\
\text { merchandise Army Bomb, photocard }\end{array}$ \\
\hline 3. & $\begin{array}{l}\text { Jihannissa Riawan } \\
\text { (Jeyhan) }\end{array}$ & 20 & Mahasiswi & $\begin{array}{l}\text { Tergabung dalam group Army Surabaya } \\
\text { Memiliki koleksi merchandise, } 3 \text { album } \\
\text { BTS, photocard, CH, CS, gantungan } \\
\text { kunci, pin, poster }\end{array}$ \\
\hline 4. & $\begin{array}{l}\text { Eza Putri } \\
\text { Mardiansyah } \\
\text { (Adori) }\end{array}$ & 19 & Karyawan & $\begin{array}{l}\text { Tergabung dalam group Army Surabaya } \\
\text { Memiliki koleksi merchandise, } 2 \text { album } \\
\text { BTS, } 7 \text { boneka BT21 }\end{array}$ \\
\hline 5. & $\begin{array}{l}\text { Natalia Fransisca } \\
\text { (Natalia) }\end{array}$ & 21 & Mahasiswi & $\begin{array}{l}\text { Tergabung dalam group Army Surabaya } \\
\text { Memiliki } 10 \text { album BTS dan koleksi } \\
\text { merchandise, serta puluhan koleksi } \\
\text { papercup dan photocard }\end{array}$ \\
\hline
\end{tabular}

Sumber: Hasil Penelitian, 2020 
Data penelitian ini mengisyaratkan, sebagian besar subjek penelitian tidak hanya menjadi consumer sekaligus produser terhadap teks (realitas) yang diteliti, tetapi juga terlibat dalam proses reproduksi dan sirkulasi makna sebagai bentuk loyalitas. Fans tidak lagi menjadi penonton, tetapi mereka akan membangun makna dari sebuah teks secara aktif. Bagi subjek yang rata-rata merupakan anak-anak muda urban, teks atau realitas budaya popular dipahami sebagai semacam simbol untuk mengisi rasa kekosongan dalam jiwa akan mimpi atau suatu simulacra. Mereka mengisi kekosongan tersebut dengan mengidolakan sesosok artis yang kemudian membuatnya merasa memiliki mimpi atau harapan dalam hidupnya. Kehadiran teks budaya populer tersebut membangkitkan gejala, dan gejala ini dijelaskan oleh Sugihartati (2017) sebagai neomania, yaitu rasa haus yang terus muncul untuk mengonsumsi objek baru dan bentuk-bentuk hiburan yang ditanamkan dalam jiwa melalui pencitraan, pesan, dan tontonan media.

Temuan dalam penelitian ini akan disajikan ke dalam tiga bagian yang menggambarkan preposisi tersebut, yaitu Neomania, fans yang tersimulakra; melakukan fanwar demi idola, dan tiga tahapan loyalitas Army. Ketiga bagian tersebut, secara fenomenologis, menggambarkan deskripsi pengalaman para subjek dalam menghayati realitas atau teks budaya popular, sekaligus bagaimana mereka secara aktif memberinya makna, sekaligus meresirkulasikannya.

\section{Neomania, Fans yang Tersimulakra}

Mendengar lagu atau menonton klip video BTS merupakan rutinitas keseharian Adori. Meski sudah ratusan kali ditonton, dia merasa tidak pernah bosan. Meski hariharinya dipadati agenda kuliah, dia tidak merasa terganggu dengan aktivitasnya sebagai Army, tetapi malah menjadi penyemangat untuk menjalani hari. Bahkan setiap hari Adori selalu mencari tahu kabar sang Idola. Meski tidak pernah bertemu secara langsung, Adori merasa memiliki ikatan hubungan yang tidak dapat dijelaskan dengan kata-kata. Adori menyukai member BTS yang bernama Kim Taehyung. Menurut Adori member Taehyung adalah kekasih virtual.

"Meski gak pernah ketemu, tapi Taehyung Oppa itu pacarku, aku jatuh cinta cuman dari lihat layar aja. Gak cuman karena gantengnya sih, tapi lagu yang dinyanyiin itu juga buat aku senang. Terutama arti dari liriknya yang buat aku dulu pas baru putus cinta bisa move on. Aku dengerin lagu Fake Love waktu itu, sampai nangis sih, dan besoknya aku mulai cari tau tentang BTS sampai akhirnya memutuskan kalau Taehyung itu pacar baruku." (Adori, 22/11/2020)

Bagi Adori, BTS adalah motivator, setiap hari melihat wajahnya saja sudah membuatnya bersemangat. Bahkan, seperti bisa dilihat dalam kutipan wawancara di atas, dia membentuk relasi imajiner dengan idolanya. Hingga akhirnya Adori memasang poster BTS di kamarnya, serta mengoleksi semua karakter boneka BT21 dari BTS untuk menghiasi tempat tidurnya.

"Di kamarku kan aku pajang poster, di handphoneku udah pasti pasang wallpaper fotonya BTS. Nah udah pasti tiap hari bangun tidur dan mau tidur ngeliat BTS terus. Kalau aku sedih, ya aku ngeliat BTS aja, nanti pasti seneng lagi. Ada sih ceritanya waktu aku ikut ujian SMBPTN kemarin. Motivasiku itu loh, karena mau ketemu BTS ke Korea. Jadi kalau aku kuliah, aku kerja, terus sukses aku bisa punya uang lebih buat ke Korea ketemu BTS, soalnya sekarang masih belum tercapai." (Adori, 22/11/2020) 
Pengalaman yang sama juga dialami Jeyhan. Tiap malam sebelum tidur dia pasti mendengarkan lagu BTS dan membayangkan guling di sampingnya adalah Jungkook, member BTS yang dia sukai.

"Aku suka membayangkan sendiri di kamar gitu, sambil dengerin lagunya. Suka bayangin aku ada di dalam video clipnya gitu loh. Sok-sok an merasa kayak aku ada di dalam ceritanya, jadi cewek yang ada di MV nya itu. Terus habis itu nangis sendiri terbawa baper ke alur ceritanya. Kadang kan juga aku tau arti liriknya, semisal lagunya yang patah hati gitu, ya aku ngebayangin patah hati juga. Aku suka ngayal-ngayal sendiri bikin cerita di pikiranku, meski kayak aneh, tapi aku seneng loh, bagiku seh beneran seru bikin moodku naek." (Jeyhan, 29/11/2020)

Dalam pikiran Jeyhan, menciptakan dunia fantasi sendiri adalah sensasi kebahagiaan yang dapat membuatnya menjadi berdebar. Meski tidak pernah bertemu BTS secara langsung, namun melalui euforia yang diciptakan sendiri membuat Jeyhan memiliki perasaan cinta terhadap Jungkook BTS. Merujuk Fiske (dalam Sugihartati, 2017) bahwa fans tidak hanya menjadi consumer sekaligus produser, namun fans juga terlibat dalam proses reproduksi dan meresirkulasi makna. Dalam konteks ini, Jeyhan maupun Adori bisa dilihat telah membuat dunia fantasinya sendiri tentang kehadiran sang idola ke dalam kehidupannya yang ada di ruangan kamarnya sendiri.

Bagi Adori, mengoleksi barang-barang BTS adalah wajib, karena barang-barang tersebut mengingatkannya tentang kenangan masa lalu saat berusaha mendapatkan barang tersebut. Contohnya, ketika membuka kembali album yang dia miliki, Adori dapat mengingat saat album tersebut dibeli bertepatan pada saat Adori lulus sekolah. Selain itu juga mengingatkan Adori tentang perjalanan idolanya sampai pada tahap perilisan album tersebut. Karena setiap album BTS itu memiliki cerita, dan cerita itu dianggapnya terhubung dengan apa yang dialaminya.

Saat ini, Adori berkuliah di Jurusan Akuntansi Universitas Surabaya. Jurusan yang dipilihnya juga terkait dengan BTS. Saat membuka laman Instagram pada Juli 2020, Adori melihat postingan dari fan page BTS yang mengatakan bahwa Taehyung (salah satu anggota BTS) memiliki kriteria wanita idaman yang dapat mengatur keuangan. Seketika itu pula Adori memutuskan memilih Jurusan Akuntansi. Sejak bergabung dengan Fandom Army, Adori punya banyak teman baru dari berbagai kota. Dia merasa, fandom Army sangat kompak, selalu peduli dengan satu sama lain, khususnya dalam hal berdonasi. Bagi Adori, komunitas Army sangatlah royal dalam berdonasi untuk kegiatan sosial. Army melakukan itu karena melihat BTS juga kerap menunjukkan rasa peduli terhadap sesama dan sering berdonasi.

Meminjam ungkapan Rakhmat (2012: 216), terpaan media massa dapat menimbulkan efek perubahan perilaku manusia setelah diterpa oleh pesan media. Di sinilah Army tampak diterpa oleh pesan yang disampaikan melalui lagu, sehingga mengubah perilaku pendengarnya. Sugihartati (2017) mengungkapkan, teks budaya populer yang dikonsumsi anak muda urban (dalam hal ini fans), merupakan simbol untuk mengisi rasa kekosongan dalam jiwa akan mimpi atau suatu simulakra, sehingga fans mengisi kekosongan tersebut dengan mengidolakan sesosok artis yang kemudian membuatnya memiliki mimpi atau harapan dalam hidupnya. Kehadiran teks budaya populer tersebut membangkitkan sebuah gejala, dan gejala ini dijelaskan oleh Sugihartati 
sebagai neomania, yaitu rasa haus yang terus menerus muncul untuk mengonsumsi suatu objek baru dan bentuk-bentuk hiburan yang ditanamkan dalam jiwa melalui pencitraan, pesan, dan tontonan media.

Hal ini misalnya tampak pada Adori, Tita, atau Jihan yang memiliki kebiasaan selalu mengecek informasi tentang BTS setiap hari. Tita merasa harinya tidak berwarna jika tidak mendengar kabar tentang sang idola atau tidak melihat wajahnya. Tita menjelaskan, perasaannya akan selalu ingin tahu dan memikirkan perkembangan sang idola. Meminjam Sugihartati (2017), perasaan khawatir agar tidak ketinggalan informasi tentang idolanya, membuat penggemar menjadi adiktif untuk terus mengikuti perkembangan informasi dari idolanya. Mereka pada umumnya akan meluangkan waktu untuk membuka situs yang terkait dengan idolanya, atau bahkan mereka akan berdiskusi dengan kelompok penggemar agar mendapatkan informasi tentang idolanya.

"Biasanya sih aku setiap bangun tidur langsung ngecek Grup WhatsApp Official Army Surabaya, karena pasti selalu ada aja berita atau info tentang doi. Yang pasti ngebahas itu tentang Video MV yang baru atau yang lama juga bisa, terus kadang ngucapin Good Morning sesama anggota tapi pakai foto member BTS yang di edit jadi kesannya yang ngucapi itu doi gitu loh. Memang kedengarannya alay cuman ya kita memang suka saling support dengan cara begitu. Dan info yang kalau dari grup itu biasanya sampai hal kecil tentang idola itu kita bisa tau, yang diberita gak ada." (Tita, 09/11/2020).

Bukan hanya Adori, tetapi para anggota yang ada pada grup tersebut saling mengucapkan salam, berbagi informasi, dan saling mendukung. Adori merasa grup ini sangat bermanfaat, karena juga menambah relasi. Tita juga mengungkapkan, dia mendapat kekuatan baru karena BTS dan Army. Karena setiap hari selalu ada teman yang sejalan, sehingga mereka tidak pernah merasa sendiri. Fandom merupakan suatu kumpulan orang yang memiliki minat atau kesenangan yang sama akan suatu hal, dan berkumpul untuk sama-sama merayakan kesenangan mereka akan minat yang sama tersebut. Fandom ditandai dengan perasaan yang sama dengan suatu kesamaan dan perasaan kedekatan. Merujuk Sagita \& Kadewandana, 2018), fandom merupakan aspek tentang bagaimana kita memahami dunia yang berkaitan dengan media massa, sejarah, sosial, dan budaya. Hal tersebut merupakan pengalaman yang membentuk makna tersendiri bagi setiap individu. Setiap orang tidak akan sama dalam memaknai suatu hal, tetapi di dalam Fandom Official Army Surabaya ini Tita merasa dapat bertukar pikiran, berdiskusi, dan sama-sama memaknai hal yang mereka minati. Sehingga menghasilkan suatu makna tersendiri bagi mereka yang berada di fandom yang sama.

Bagi Tita berbagi sesuatu hal di dalam grup sangatlah bermanfaat. Bagi Tita, grup fandom harus ada, karena dapat membantu memberikan informasi penting, yang bahkan di berita media massa belum ada, tetapi Tita dapat mengetahui dan membahasnya samasama dengan sesama Army. Dalam pemahaman Tita, BTS mengajarkan kepada Army untuk mencintai diri sendiri dan bahwa sukses butuh perjuangan. Selain itu juga ada makna healing atau penyembuhan melalui lagunya, yang membuat orang yang sebelumnya merasa insecure menjadi percaya diri. Contohnya lagu Magic Shop. Tita memiliki pengalaman terkait lagu ini yang membuatnya menjadi bangkit kembali. Tita pernah memiliki pikiran untuk bunuh diri karena insecure, tapi batal melakukannya karena terinspirasi lagu BTS dan membuatnya menjadi percaya diri. Hal inilah yang 
membuat Tita menganggap BTS adalah penyelamat hidupnya. Karena itu Tita mencintai BTS sepenuh hati. Baginya BTS patut dikagumi bukan hanya dari pesonanya, namun makna lagunya dapat mengubah seseorang menjadi lebih baik dan itu terjadi pada dirinya.

"Mereka mengajarkanku untuk mencintai diri sendiri melalui album "Love Yourself” dan ngasih tau kalau sukses itu butuh perjuangan. Aku ngerasa ada makna healing atau penyembuhan melalui lagunya, yang membuat aku dulunya insecure menjadi percaya diri lagi. Salah satu contoh adalah lagu "Magic Shop", menurutku lagu ini memang punya magic karena dulu aku sempat depresi dan berpikir mau mencoba untuk bunuh diri karena insecure, tapi akhirnya aku sadar dan terinspirasi dari lagu BTS yang Love Yourself itu. Bikin aku jadi mencintai diriku dan mulai bersyukur. Bagiku BTS mencintai Army, ya sama aja aku juga dicintai oleh mereka. Pasti mereka sedih kalau sampai tau ada Army yang bunuh diri." (Tita, 09/11/2020).

Selama ini, Tita tidak mempunyai teman di sekolah yang membuatnya merasa kesepian dan menimbulkan rasa insecure. Tita merasa ada kekosongan dalam jiwanya yang kemudian diisi dengan pesan yang tersampaikan melalui lagu BTS. BTS mengisi posisi kekosongan itu yang membuat Tita akhirnya mencintai BTS. Itu sebabnya Tita memaknai hubungannya dengan BTS dilandasi rasa cinta dan peduli antara fans dan idol. Hal ini tergambar dari pembicaraan Tita yang mengungkapkan bahwa BTS akan sedih jika mengetahui ada Army yang hendak bunuh diri.

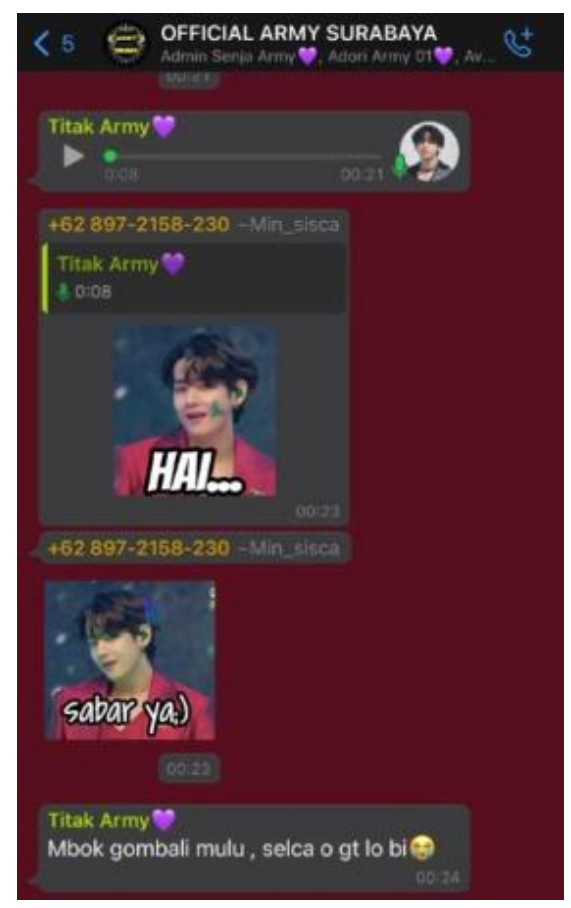

Sumber: Dokumentasi peneliti, 2020.

\section{Gambar 3 Screenshoot Official WA Group Army Surabaya}

Hari-hari Tita diisi chat dengan Fandom Army yang berisi ucapan kasih sayang, yang meski disampaikan oleh sesama Army namun dia tetap merespons seperti seolah sang idola sendiri yang memberi pesan tersebut karena pesan disampaikan dengan gambar sang idola. Jihan pun memiliki kebiasaan serupa dengan Tita; tidak pernah lepas dari informasi tentang BTS. Media sosial yang digunakan setiap hari pasti selalu ada informasi tentang BTS. Jihan merasa berkewajiban mengetahui kabar "pacarnya" setiap 
hari. Setiap hari yang ada dalam pikirannya adalah kabar sang idola, bahkan memikirkan idola ini sudah melebihi dari memikirkan kehidupan nyatanya.

Dalam kehidupan sehari-hari, fans terlihat terjebak pada pesona idolanya. Dalam hal ini, Army tidak dapat terlepas dari pesona BTS, sehingga kehidupannya konstan diisi dengan kekaguman terhadap sosok idolanya. Adori pernah memiliki pengalaman terkait hal itu. Suatu sore, 14 Juni 2020, BTS menggelar Live Streaming "Bang Bang Con." Adori memberi tiketnya seharga Rp. 497.000. Dengan wajah ceria seperti diperlihatkan ketika ditemui peneliti melalui wawancara online via video call, Adori menceritakan detail kegiatannya pada hari itu.

"Jadi saat mau liat nonton live "Bang Bang Con" waktu itu tuh, aku semalem udah ijin sama mamaku. Aku bilang "mah besok aku seharian mau nonton konser BTS online jadi biarin aku dikamar terus ya, jangan di suruh-suruh”. Mamaku sih ngijinin, tapi dikasih syarat paginya aku harus bersih-bersih rumah dulu ya. Yauda sih besoknya aku cepet-cepet bangun terus bersih-bersih dan bener aja sih aku setelah itu langsung diem di kamar terus sampai lupa makan. Meski cuman liat dari layar, gak tau kenapa suasananya itu dapet banget, kayak lagi nonton konser beneran dan sampai teriak-teriak sendiri." (Adori, 22/11/2021)

Adori masih bisa mengingat perasaannya saat menonton konser itu; badannya merinding. Meski hanya dilihat melalui layar kaca, suasana konser mendebarkan hati Adori. Hanya dengan sendirian di kamar, menutup pintu rapat-rapat, menggunakan layar laptop 14 inchi, dan mengencangkan suara musik menggunakan speaker, sudah cukup bagi Adori untuk membuat suasana konser sendiri di rumah. Mengutip Booth (dalam Sugihartati, 2017) kehadiran teknologi informasi membuat adanya kesempatan dan keleluasaan fandom menjadi generasi techno-literate di mana mereka dapat merayakan pengalaman mereka dengan menggunakan teknologi. Mereka dapat mengkreasi dan menciptakan pengalaman dalam ruang virtual yang diciptakannya.

Jenkins (dalam Sugihartati, 2017) mendefinisikan, kreativitas fandom tercipta dari production-comsumption, namun eksistensi subkultur fandom saat ini telah dipengaruhi oleh penggunaan internet sehingga space dan place terbentuknya telah melampaui kelokalan menjadi translokal dan virtual. Adori adalah seorang Army yang berasal dari Indonesia di kota Surabaya, sedangkan BTS berada di Korea Selatan. Namun hal tersebut tidak membatasi Adori untuk tetap dapat menikmati konser BTS secara virtual dan menghayati keberadaan idolanya.

\section{Melakukan 'Fanwar' Demi Kekasih Virtual}

"Lagu-lagu BTS membuatku berjuang untuk diri sendiri, aku langsung mengikrarkan diri menjadi istrinya. Senyumnya itu loh manis, terus genius, lagu-lagu yg dia bikin dalam banget maknanya, kadang dia dingin kadang hangat, aku gak tau kenapa bisa sesuka ini ama dia tiap liat dia itu kayak ngerasa adem ajah gitu" (Senja, 29/11/2020)

Sejak melihat BTS pertama kali, Senja seketika jatuh cinta; dan menganggap BTS adalah suami virtual. Bagi Senja, BTS telah menempati posisi sebagai pasangan kekasih dalam hidupnya. Apalagi hingga saat ini, belum ada sesosok pria yang bisa menggantikan posisi BTS dalam kehidupan nyatanya. Sama dengan Adori mengenai BTS sebagai pasangan hidup virtual, Senja bahkan setiap hari mengucapkan selamat malam pada 
poster Taehyung di kamarnya. Baginya, saat ini tidak ada yang dapat menggantikan posisi BTS dalam hidupnya.

"Kalau nanti punya pacar, takutnya dilarang buat suka BTS gitu, kan biasanya banyak orang yang gak suka sama K-Pop mikirnya aneh. Makanya sekarang sih ya aku gak mau punya pacar dulu, takut gak bisa bucin (budak cinta) ke BTS lagi." (Senja, 29/11/2020)

Senja mengungkapkan, begitulah perasaannya saat ini hingga masih tidak berpikiran untuk berpacaran dahulu karena rasa cintanya kepada BTS. Bagi Senja (maupun Adori), mencintai sang idola juga termasuk ditunjukkan dengan cara membela sang idola. Adori pernah bertengkar dengan sesama fandom lain, atau yang dalam kajian fandom sering disebut fanwar. Fanwar merupakan aktivitas perang antara fans di media sosial. Salah satu fanwar yang pernah dialami Senja adalah berdebat melalui komentar di Twitter. Bagi Senja, membela BTS adalah hal yang wajib dilakukan, seperti seorang istri yang membela suami ketika ada hal buruk terjadi.

"Ya aku sih cerita pengalaman aku pernah fanwar, cuman yang gak sampai gimana gitulah. Pernah itu bacot-bacotan di Twitter sama fansnya boyband tetangga gitu loh. Di sini aku sih gak suka aja kalau saling menjatuhkan atau menjelekkan idol kita, kan itu hak masing-masing orang ya mau suka sama siapa. Cuman aku kesel aja kalau ada yang sirik dengan hidup orang lain malah menjatuhkan. Mereka itu membanding-bandingkan bias mereka dengan biasku tentang siapa lebih baik dan lebih ganteng. Ya ganteng itu relatif, pendapat individu, tapi jangan sampai ngomong bias orang lain jelek di publik, itu termasuk pencemaran nama baik, dan aku gak terima aja langsung aku balesin. Membela itu penting kak, karena Idol kita udah berjuang juga, aku gak mau mereka down kalau sampai membaca hate comment banyak orang yang gak kuat bisa bunuh diri. That's why aku gak mau kalau sampai BTS juga down. Selama aku bisa melindungi mereka, kenapa enggak gitu loh." (Senja, 29/11/2020)

Senja sebagai seorang fans tidak segan memberikan komentar pembelaan pada idolanya tanpa melihat bahwa artis idolanya benar ataupun salah. Baginya, loyalitas juga dapat dibuktikan melalui perbuatan, seperti membela idola sepenuhnya. Fans memang didefinisikan sebagai pengikut yang antusias atau seseorang yang memiliki rasa kagum dan simpati yang besar terhadap idolanya yang secara aktif mengumpulkan informasi mengenai idolanya serta mendukung idolanya dengan menempatkannya dalam prioritas tertinggi di dalam aktivitas di hidupnya dan berpikiran, berperasaan, dan bertingkah laku ekstrem (Sari, 2012). Di kalangan fans BTS, peneliti menemukan bahwa sebagian besar anggota tidak hanya menjadi konsumer sekaligus produser, tetapi juga terlibat dalam proses reproduksi dan meresirkulasi makna. Fans tidak lagi menjadi penonton, tetapi juga akan membangun makna dari sebuah teks secara aktif. McCudden (2011) menyebutkan, aktivitas fans adalah membuat makna (meaning making), berbagi makna (meaning sharing), berburu (poaching), mengumpulkan (collecting) dan membangun pengetahuan (knowledge building) sebagai aktivitas fans. Dalam konteks ini, apa yang dilakukan Senja bisa diletakkan dalam konsepsi McCudden seperti bisa dilihat dalam tabel berikut.

Tabel 2 Aktivitas Army Surabaya

\begin{tabular}{|l|l|}
\hline \multicolumn{1}{|c|}{ AKTIVITAS FANS } & \multicolumn{1}{|c|}{ AKTIVITAS ARMY SURABAYA } \\
\hline $\begin{array}{l}\text { Membuat Makna (Meaning Making): } \\
\begin{array}{l}\text { Terlibat aktif membuat makna dan } \\
\text { menginterpretasikan makna tersebut melalui teks }\end{array}\end{array}$ & $\begin{array}{l}\text { Memaknai lagu BTS sesuai dengan pendapat atau } \\
\text { pengalaman hidupnya sendiri. }\end{array}$ \\
\hline
\end{tabular}




\begin{tabular}{|c|c|}
\hline $\begin{array}{l}\text { media, dan menggabungkannya dengan } \\
\text { pengalaman dan emosi yang dimiliki oleh fans. }\end{array}$ & \\
\hline $\begin{array}{l}\text { Berbagi Makna (Meaning Sharing): } \\
\text { Membagi makna yang dirumuskan kepada sesame } \\
\text { fans. }\end{array}$ & $\begin{array}{l}\text { Membagikan makna tersebut kepada orang lain, } \\
\text { seperti teman atau sesama fandom, bahwa BTS } \\
\text { adalah idol yang positif. }\end{array}$ \\
\hline $\begin{array}{l}\text { Berburu (Poaching): } \\
\text { Mencontoh atau mengambil sebuah teks (bisa } \\
\text { berupa lirik atau cerita tentang idol), } \\
\text { menggunakan potongan teks tersebut untuk } \\
\text { membuat cerita dan menjadi ide kreasi mereka } \\
\text { seperti fan fiction. }\end{array}$ & $\begin{array}{l}\text { Mencari lirik lagu atau cerita tentang BTS dan } \\
\text { menggunakannya sebagai dasar untuk membuat } \\
\text { kegiatan kreatif lalu dibagikan ke media sosial. }\end{array}$ \\
\hline $\begin{array}{l}\text { Mengumpulkan (Collecting): } \\
\text { Mengumpulkan barang-barang, produk, atau } \\
\text { merchandise terkait idola.. }\end{array}$ & $\begin{array}{l}\text { Mengumpulkan sebanyak mungkin koleksi } \\
\text { album-album atau merchandise BTS. Hal ini } \\
\text { menjadi sebuat tolak ukur kegemaran, bukan } \\
\text { dilihat dari nilai barang secara individu. }\end{array}$ \\
\hline $\begin{array}{l}\text { Membangun Pengetahuan (Knowledge } \\
\text { Building): } \\
\text { Mengumpulkan pengetahuan tentang idola yang } \\
\text { menjadi fokus kegemaran melalui berbagai } \\
\text { sumber, seperti biografi, fandom, internet, sosial } \\
\text { media. }\end{array}$ & $\begin{array}{l}\text { Mengumpulkan pengetahuan atau informasi } \\
\text { tentang BTS, dan mengukur tingkat kegemaran } \\
\text { fans lain dengan pengetahuan yang dimiliki } \\
\text { tentang sejarah objek yang dikagumi. }\end{array}$ \\
\hline
\end{tabular}

Sumber: Hasil Penelitian, 2020

Melalui aktivitas tersebut bisa dilihat, Army bukan sekedar mengonsumsi makna, tetapi juga menyirkulasikan_dan memproduksi makna terkait idolanya. Seperti diceritakan Jeyhan, dirinya pernah melakukan fanwar dengan fans lain. Baginya, seorang fans memiliki cara pandang yang berbeda untuk mengagumi setiap idolanya, tetapi tidak seharusnya para fans saling menghakimi atau menilai buruk idola orang lain.

"Dulu itu pernah di Twitter, fansnya si idol lain itu ngomong kalau BTS itu loh menang awardnya nyogok. Juga BTS itu loh perjuangannya gak ada. Ya aku otomatis baca kayak gituan jadi emosi, mereka gak tau perjuangannya BTS dari nol kayak apa, kita Army ya udah ngikuti dari mulai debut, kita merasa ikut ngesupport sampai sekarang ya gak terima aja kalau mereka diluaran sana nuduh yang enggak-enggak ya pasti kulawan." (Jeyhan, 29/11/2020)

Bagi Jeyhan, membela idola sudah dianggap seperti membela kekasihnya sendiri, karena selama ini BTS dirasa telah menemani hari-harinya, dan membuat Jey bersemangat menjalani hidupnya. Bagi Jeyhan, BTS juga pasti punya perasaan, jika sampai mendengar komentar pedas akan membuat BTS merasa down. Pada titik ini, loyalitas dipahami Jeyhan sebagai kesiapan dan kesediaan melakukan pembelaan terhadap idola. Seorang fans, menurut dia, bertugas mendukung idola. Sebagai seorang Army, Jeyhan juga turut mendukung BTS melalui vote dan juga streaming. Dengan begitu, dia merasa ikut berkontribusi mendorong jumlah vote yang didapat oleh BTS

\section{Tiga Tahapan Loyalitas Army}

Para fans ini, seperti dikatakan Stanley (dalam Hurriyati, 2010), memiliki hubungan loyalitas yang sampai pada tahapan The Relationship, The Courtship dan The Marriage. Konsepsi ini menjelaskan bahwa fans memiliki loyalitas yang dibagi dalam 3 tahapan. Dari hubungan yang hanya sekedar sebagai fans yang masih bisa menahan rasa 
ingin untuk memenuhi gaya hidup sebagai fans, hingga The Marriage hubungan yang terjalin bukan lagi sekedar keinginan untuk bertransaksi semata, melainkan telah terciptanya hubungan jangka panjang yang tidak dapat memisahkan kedua belah pihak dan terbentuknya loyalitas karena adanya tingkat kepuasan yang tinggi, sehingga tercipta rasa ketergantungan fans pada idola.

Pada tahap The Courtship, fans menjalin hubungan dengan idola masih sebatas pada tahapan transaksi. Fans masih mempertimbangkan uang yang akan dikeluarkan apakah sepadan dengan yang didapat. Di tahap ini fans masih memikirkan apakah biaya yang dikeluarkan masih selaras dengan kebutuhannya. Meski ingin memiliki album atau produk idola, fans masih memikirkan apakah keinginan tersebut merupakan prioritas atau tidak dalam hidupnya. Data penelitian ini menunjukkan, para subjek penelitian sudah tidak berada di tahapan ini.

Sebagian subjek penelitian terlihat berada pada tahapan The Relationship, di mana hubungan antara fans dan idola mulai tercipta, di antaranya melalui kesediaan atau kerelaan membeli produk-produk terkait idola. Jeyhan misalnya, bersedia menabung agar bisa mengumpulkan koleksi album BTS serta koleksi lain photocard, $\mathrm{CH}, \mathrm{CS}$, ganci, pin, atau poster. Untuk album, dia mengaku membelanjakan uang satu juta rupiah, sedangkan untuk koleksi lain dia mengeluarkan dana sampai 2 juta rupiah. Dia juga rela mengeluarkan dana untuk membeli kuota internet agar bisa menonton reality show BTS atau video klip BTS. Jeyhan tidak merasakannya sebagai beban, karena dia merasa hal tersebut memberikan kebahagiaan tersendiri. Dia merasa, semua kegiatan fangirling yang dilakukannya sama sekali tidak mengganggu, karena bisa membuatnya semakin bersemangat menjalani aktivitas.

Hal serupa dirasakan Adori dan Tita. Keduanya menunjukkan loyalitasnya juga dengan cara membelanjakan uangnya untuk membeli produk BTS tanpa lagi memperhitungkan harga. Mereka bahkan mengaku rela berpuasa dan menabung demi membeli produk BTS. Untuk melengkapi koleksinya, Tita telah menghabiskan uang sekitar 5 juta rupiah yang ia tabung dari uang jajannya. Tapi Tita tidak pernah merasa menyesal, karena dia memang menabung khusus untuk membeli hal tersebut. Ia bahkan ingin, jika nanti sudah bekerja bisa membeli koleksi lain.

Sedangkan The Marriage merupakan tahapan yang bukan lagi sekadar keinginan untuk bertransaksi semata, melainkan telah terciptanya hubungan jangka panjang yang tidak dapat memisahkan kedua belah pihak dan terbentuknya loyalitas dikarenakan adanya tingkat kepuasan yang tinggi, sehingga tercipta adanya rasa ketergantungan fans pada perusahaan. Tahapan ini terlihat terjadi kepada Natalia. Dia menghabiskan waktunya setiap hari dengan bekerja, namun tidak pernah merasa bahwa waktunya tersita meski menjadi seorang Army. Setiap usai kerja, Natalia menghabiskan waktu untuk berselancar di internet melakukan fangirling seperti menonton Youtube, Twitter, Weverse, membaca Fanfict, melihat Instagram. Selama melakukan fangirling, Natalia juga harus mengeluarkan biaya seperti membeli kuota dan fanbook. Baginya mengeluarkan uang bukanlah masalah, karena uang tersebut tergantikan oleh perasaan bahagia yang tidak dapat digantikan oleh apapun. Natalia merasa, selama ini BTS membuatnya menjadi pribadi yang lebih baik, lebih mencintai diri sendiri, merasa beruntung punya banyak teman, dan lebih bersemangat menggapai apa yang diinginkan. 
"Menjadi fans tentu harus memiliki sikap loyalitas, aku gak pernah menggemari sesuatu hal seantusias ini. Tapi jika sudah suka, kenapa kita gak totalitas aja? Sekalian gitu loh. Karena aku kalau suka sesuatu gak akan setengah-setengah. Kalau sudah memilih BTS sebagai penyemangat dalam hidupku ya aku akan loyalitas kepada mereka, karena mereka itu juga sudah termasuk berperan dalam hidup, contohnya ya cita-cita, karena mereka aku jadi punya ambisi dan semangat untuk menabung agar bisa nonton konsernya. Sampai akhirnya aku memutuskan berjualan online barang-barang BTS ya diawali dari tekad tersebut. Hasilnya aku jadi bisa nonton konsernya plus punya usaha yang sampai sekarang masih ditekuni." (Natalia, 28/11/2020)

Menurut Natalia, menjadi seorang fans memang harus menunjukkan kecintaannya dengan cara mengoleksi produk dari idolanya. Koleksi tersebut menandai seseorang adalah seorang fans karena memiliki barang-barang tentang sang idola. Bagi Natalia, menyukai sesuatu harus dilakukan secara totalitas. Itu sebabnya Nat mengoleksi albumalbum dari BTS, serta menghiasi kamarnya dengan poster dan foto-foto BTS. Tidak hanya itu, Natalia juga mengumpulkan papercup BTS yang disusun di atas meja kamarnya. Untuk menambah detail, dia memberikan warna ungu dan lilac untuk nuansa kamar, karena BTS identik dengan warna ungu.

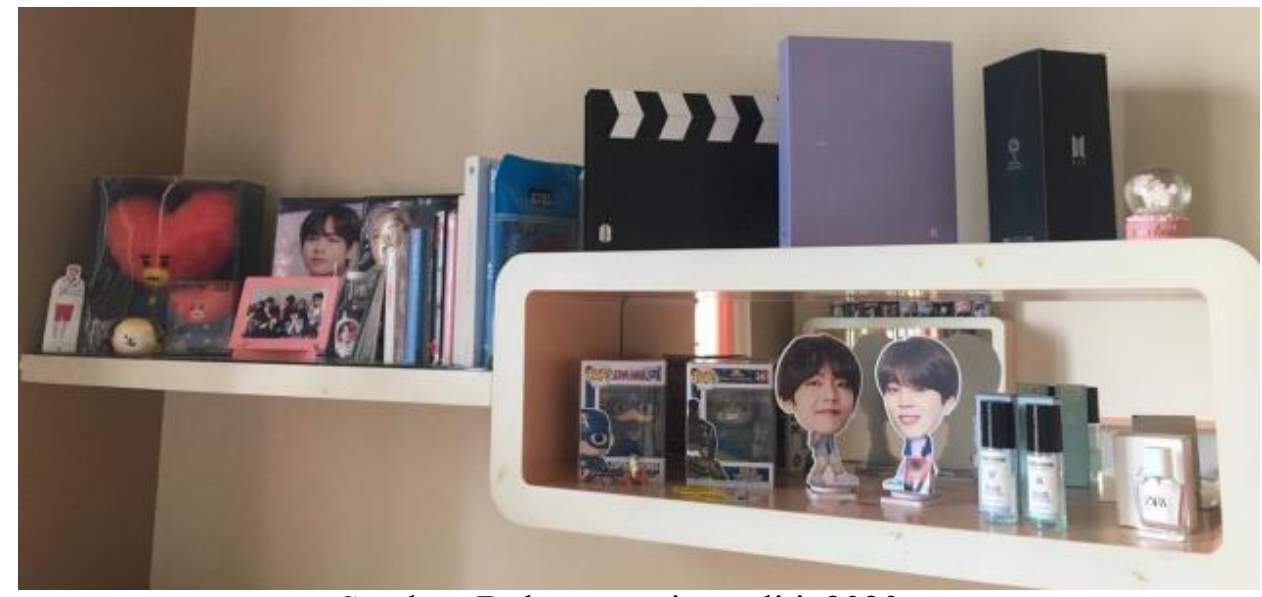

Sumber: Dokumentasi peneliti, 2020.

Gambar 4 Koleksi Merchandise BTS di Kamar Natalia

Fans adalah produsen aktif sekaligus konsumen modal budaya (Sari, 2012). Jika fans dikaitkan dengan kata fandom, merupakan suatu keadaan di mana seseorang menggemari sesuatu yang meliputi budaya dan perilaku fans secara umum. Fandom adalah sekelompok fans, yang berfokus pada sikap kefanatikan. (Redhead dalam Sagita \& Kadewandana, 2018). Fans akan merasa tidak diakui identitasnya sebagai penggemar tanpa adanya barang-barang koleksi yang dimiliki.

Hal ini menjadi sama dengan apa yang dikatakan Yuniarti (2015) bahwa perilaku konsumtif telah menjadi budaya dalam pemenuhan gaya hidup. Gaya hidup yang dimaksud adalah fans, di mana fans membutuhkan kegiatan memenuhi gaya hidupnya sebagai fans, hal inilah yang berkaitan dengan sikap loyalitas dimana fans akan selalu mendukung idolanya melalui kegiatan membeli koleksi.

Menurut Natalia, loyalitas penting dimiliki oleh fans karena menjadi fans itu artinya menggemari sesuatu, dan sudah sepantasnya menggemari sesuatu itu secara totalitas. Perilaku tersebut yang muncul dari fans secara tidak langsung membentuk 
sebuah loyalitas di mana fans mengeluarkan uangnya demi idola yang mereka cintai. Merujuk McRobbie (2011), bahwa mereka memiliki keinginan dalam gaya dan kenikmatan yang membuat mereka tertarik pada produk populer. Fans yang loyal merupakan konsumen penting bagi setiap idola di Korea.

Di sinilah Senja dan Natalia terlihat telah menempati tahapan loyalitas pada tahapan The Marriage di mana pembelian yang dilakukan sudah berulang dan menjadi hubungan jangka panjang antara mereka dengan BTS. Senja dan Natalia sudah tidak memikirkan lagi soal harga dari album yang baru rilis, mereka akan melakukan pembelian tanpa berpikir panjang. Senja mengungkapkan bahwa dia ingin mempunyai semua album BTS secara lengkap, dan Natalia pun menyatakan akan melengkapi semua koleksinya. Meski kamarnya sudah penuh, Nat tetap ingin memiliki segala bentuk barang-barang BTS.

Dalam pemahaman Senja, loyal terhadap BTS merupakan hal yang harus dilakukan fans, karena Army memang ada untuk mendukung BTS. Bentuk dukungan yang diberikan adalah dengan membeli album atau produk tentang BTS. Bagi Senja, BTS telah berjuang untuk memberikan penampilan terbaik, selalu berlatih untuk tampil di show, dan telah berjuang untuk menjadi seperti saat ini. Karena itu, menurut Senja, tidak ada salahnya bagi Senja jika seorang Army juga harus berjuang untuk mendukung BTS. Maka mengeluarkan uang untuk membeli produk dari BTS adalah bentuk perjuangan yang tulus yang ia berikan untuk BTS.

Senja memiliki sekitar 15 album BTS. Selain itu Senja juga memiliki koleksi Army Bomb, season greeting, official membership, BT21, figure Jimin, Dicon, BTS doll. Dari semua koleksi yang dia miliki, Senja telah menghabiskan uang sekitar 10 juta rupiah lebih untuk membeli koleksi tersebut. Senja sama sekali tidak merasa menyesal membelanjakan uang sebanyak itu karena menurutnya itu adalah investasi untuk kebahagiaannya. Senja mengaku senang dan rela mengeluarkan uang tersebut, karena sebagian hasil dari penjualan album dan merchandise BTS akan disumbangkan ke "Love Myself Campaign." Dengan begitu, Senja merasa telah turut berdonasi, dan jika penjualan album mereka tinggi maka Senja merasa bangga.

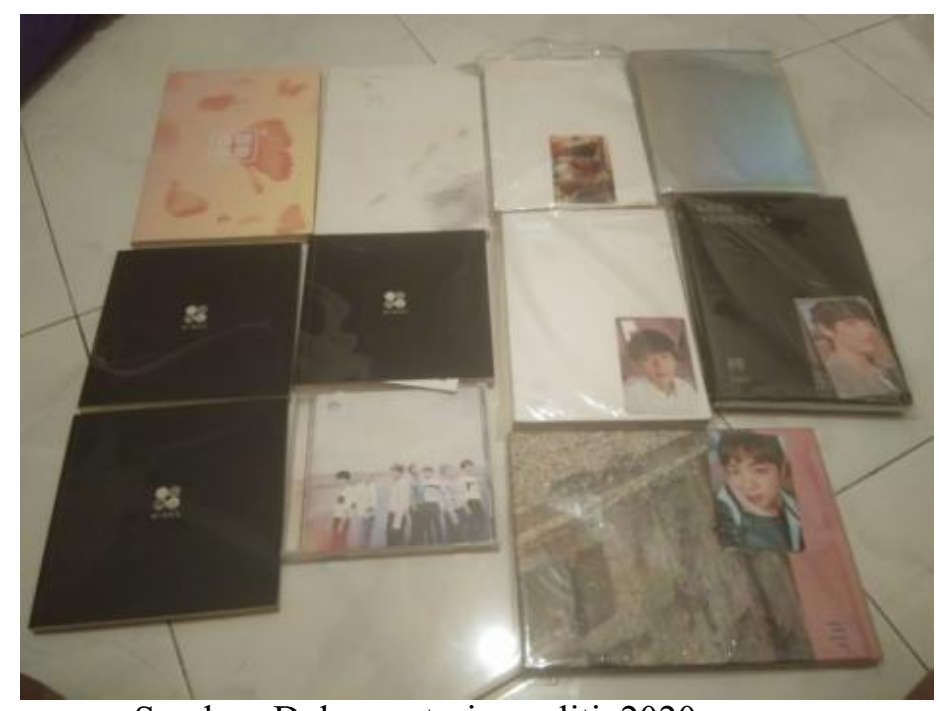

Sumber: Dokumentasi peneliti, 2020.

Gambar 5 Koleksi Album BTS Milik Senja 
Apa yang dirasakan Senja juga dirasakan Natalia. Natalia memaknai loyalitas sebagai bentuk rasa kesetiaan dan identitas bagi seorang Army. Baginya semua uang yang telah dihabiskan selama ini merupakan pembuktian rasa cintanya kepada BTS. Barangbarang tersebut memiliki kekuatan untuk menaikkan mood setiap harinya. Natalia menjadi lebih bersemangat untuk mencari uang karena ingin memenuhi koleksinya. Natalia juga memaknai loyalitas ini sebagai pembalasan atas perjuangan dan kerja keras yang telah dilalui BTS untuk bisa menjadi sebagus saat ini. Semua lagu yang disajikan oleh BTS menurut Senja memiliki makna kasih sayang yang disampaikan kepada Army serta hanya Army yang dapat merasakan perasaan yang disampaikan itu. Sehingga loyalitas yang Senja maknai adalah sebagai bentuk apresiasinya untuk BTS.

"Bagiku melakukan hal tersebut itu tidak menyusahkan aku, meski aku harus meluangkan waktu lebih ya, sampai gak ada waktu buat diri sendiri, aku sampai putus sama pacarku gegara aku terlalu sibuk ngurusin fandom ini. Aku rela demi BTS dan Army, supaya para Army di Surabaya ini bisa bersatu dan mendukung BTS. Dengan ngadain event gitu, kita jadi lebih dekat, bisa kenal satu sama lain dan bisa saling sharing. Aku bahagia melihat Army bahagia, begitu juga BTS pasti bahagia memiliki Army. " (Natalia, 28/11/2020)

Sementara bagi Senja, posisinya sebagai pemimpin dalam fandom Official Army Surabaya, hal tersebut sudah dipahami sebagai tanggung jawab. Bagi Senja, mengurus komunitas memang tidak mudah, namun dia menyanggupi hal tersebut. Dia merasa apa yang dilakukannya ditujukan untuk pujaan hatinya BTS. Untuk itu, Senja juga rela meluangkan waktu lebih demi memikirkan ide acara untuk event yang akan diadakan, Senja juga harus meluangkan waktunya untuk rapat admin serta mengeluarkan dana modal untuk pembuatan acara, seperti menyewa gedung. Meskipun harus berkorban untuk mengeluarkan hal tersebut, dia mengungkapkan tidak terbebani dan merasa melakukannya dengan senang dan ikhlas.

\section{SIMPULAN}

Army Surabaya memaknai loyalitasnya terhadap grup idolanya, BTS, sebagai bentuk kesetiaan yang wajib dilakukan secara tulus tanpa memperhitungkan biaya atau upaya yang harus dikeluarkan. Bentuk loyalitas bisa berupa membeli semua album, merchandise, produk-produk terkait BTS, atau menonton konser BTS (baik secara live maupun streaming). Meskipun mereka banyak membelanjakan uang untuk mengonsumsi beragam produk BTS, Army Surabaya tetap tidak merasa idolanya sebagai barang yang dapat dibeli dengan uang. Pembelian produk BTS cenderung dimaknai sebagai pemenuhan kepuasan serta kenikmatan, bukan menghamburkan uang. Army Surabaya juga memaknai hal-hal tersebut sebagai euforia atau ekspresi rasa bahagia tanpa batas, dna tidak bisa digantikan yang lain.

BTS juga dilihat sebagai belahan jiwa, bahkan seperti kekasih atau suami virtual. Hal ini merupakan implikasi dari kehadiran teknologi informasi yang kian memberi keleluasaan para fans untuk menjadi generasi techno-literate, yang mampu merayakan pengalaman dengan menggunakan teknologi. Melalui teknologi informasi, Army Surabaya mampu menciptakan atau mengkreasikan pengalamannya melalui dunia virtual, yang kemudian memunculkan situasi yang disebut neomania, yaitu perasaan haus yang 
terus-menerus untuk mengonsumsi objek hiburan melalui citraan, pesan, dan tontonan media.

Riset ini juga mendapatkan hasil, anggota Army Surabaya yang menjadi subjek penelitian ternyata tidak hanya menjadi consumer, tetapi juga sekaligus menjadi produser yang melibatkan diri dalam proses reproduksi dan sirkulasi makna loyalitas. Tidak hanya sekadar menjadi penonton, para fans ini juga ikut aktif membentuk makna. Riset ini juga menemukan, para subjek penelitian ikut melakukan aktivitas yang disebut meaning making (menciptakan makna melalui syair lagu BTS; meaning sharing (berbagi makna dengan sesama fans melalui media sosial; poaching (mencari) untuk mengumpulkan (collecting) informasi dan membangun pengetahuan (knowledge building).

\section{UCAPAN TERIMA KASIH}

Penulis mengucapkan terima kasih kepada Agata Winda, S.Sos., M.A. yang ikut memberi masukan yang berharga pada naskah ini. Penulis juga menyampaikan apresiasi terhadap redaksi Jurnal Avant Garde dan reviewer yang telah memberi masukan berharga untuk mempertajam naskah ini.

\section{DAFTAR PUSTAKA}

Arundati, N., Vania, A. A., \& Arisanti, M. (2019). Perilaku Celebrity Worship pada Anggota Fandom EXO dalam Komunitas EXO-L Bandung. Komunikasi, 13(1), 53-72.

Barnawi, \& Darojat, J. (2018). Penelitian Fenomenologi Pendidikan; Teori dan Praktik. Sleman, Yogyakarta: Ar-Ruzz Media.

Cho, C. (2012). "K-pop still feels impact of Seo Taiji \& Boys". The Korea Herald. Retrieved April 12, 2016.

Cindoswari, A. R., \& Diana, D. (2019). Peran Media Massa Terhadap Perubahan Perilaku Remaja Di Komunitas Kpopers Batam. Jurnal Komunikasi Universitas Garut: Hasil Pemikiran dan Penelitian, 5(2), 275-285.

Fiske, J. (2011). Memahami Budaya Populer. Yogyakarta: Jalasutra.

Hapsari, P. W., Manurung, S. M., \& Dewi, P. A. (2016). Perilaku Konsumsi dan Produksi Komunitas Penggemar Musik Vocaloid di Jepang 2008-2012. Wahana, 1(12), 44-52.

Hurriyati, R. (2010). Bauran Pemasaran dan Loyalitas Konsumen. Bandung: Alfabeta.

Jenkins, H. (1992). Textual Poachers: Television Fans \& Participatory Culture. New York: Routledge.

Juwita, S. H. (Juli 2018). Tingkat Fanatisme Penggemar K-Pop Dan Kemampuan Mengelola Emosi Pada Komunitas Exo-L Di Kota Yogyakarta. Jurnal Riset Mahasiswa Bimbingan dan Konseling, 4(7), 273-286.

McCudden, M. L. (2011). Degrees of Fandom: Authenticity \& Hierarchy in the Age of Media Convergence. Doctor of Philosophy of Communication Studies Faculty of the University of Kansas. Kansas: U.S.A. P.

Pertiwi, S. A. (2013). Konformitas dan Fanatisme Pada Remaja "Korean Wave" (Penelitian pada Komunitas Super Junior Fans Club ELF "Ever Lasting Friend") di Samarinda. eJournal Psikologi, 1(2), 157-166. 
Putra, A. A., \& Jusnita, R. A. (2018). Komunikasi dan Identitas Budaya Populer pada Komunitas Korean Lovers Surabaya. Jurnal Kajian Media, 2(1) , 1-11.

Rakhmat, J. (2012). Psikologi Komunikasi. Bandung: PT Remaja Rosdakarya.

Rinata, A. R., \& Dewi, S. I. (2019). Fanatisme Penggemar Kpop dalam Bermedia Sosial di Instagram. Interaksi: Jurnal Ilmu Komunikasi, 8(2), 13-23.

Robbie, A. M. (2011). Postmodernisme dan Budaya Pop. Bantul: Kreasi Wacana.

Sagita, A., \& Kadewandana, D. (2018). Hubungan Parasosial di Media Sosial (Studi pada Fandom Army di Twitter). Journal of Strategic Communication, 8(1), 4558.

Saputri, Y.D. (2019). BTS adalah Grup Idola Papan Atas Korea Selatan, Ini Fakta Menarik $\quad 7 \quad$ Membernya. Diunduh dari https://www.liputan6.com/citizen6/read/3909753/bts-adalah-grup-idola-papanatas-korea-selatan-ini-fakta-menarik-7-membernya, 11 September 2020.

Sari, R. P. (2012). Fandom dan Konsumsi Media: Studi Etnografi Kelompok Penggemar Super Junior, ELF Jogja. Jurnal Komunikasi, 6(2), 79-90.

Seidman, I. (2006). Interviewing as Qualitative Research: a Guide for Researchers in Education and The Social Sciences. New York: Teachers College Press.

Sugihartati, R. (2017). Budaya Populer dan Subkultur Anak Muda. Surabaya: Pusat Penerbitan dan Percetakan.

Veronica, M., Paramita, S., \& Utami, L. S. (2018). Eksploitasi Loyalitas Penggemar Dalam Pembelian Album K-Pop. Koneksi, 2(2), 433-440.

Widyastuti, P.R. (2018). 10 Kota dan Negara Ini Sumbang Penonton Terbanyak untuk MV BTS, Ada yang di Indonesia Lho! DIunduh dari https://www.tribunnews.com/seleb/2018/08/27/10-kota-dan-negara-inisumbang-penonton-terbanyak-untuk-mv-bts-ada-yang-di-indonesialho? page=all, 11 September 2020.

Yuniarti, V. S. (2015). Perilaku Konsumen; Teori dan Praktik. Bandung: CV Pustaka Setia. 